Published in final edited form as:

Curr Opin Crit Care. 2018 December ; 24(6): 512-518. doi:10.1097/MCC.0000000000000551.

\title{
Resuscitation Fluids
}

Jonathan D. Casey, MD¹, Ryan M. Brown, MD¹, and Matthew W. Semler, MD, MSc ${ }^{1}$

${ }^{1}$ Division of Allergy, Pulmonary and Critical Care Medicine, Vanderbilt University Medical Center, Nashville, TN

\section{Abstract}

Purpose of the Review: Intravenous fluid administration is a fundamental therapy in critical care, yet key questions remain unanswered regarding optimal fluid composition and dose. This review evaluates recent evidence regarding the effects of fluid resuscitation on pathophysiology, organ function, and clinical outcomes for critically ill patients.

Recent findings: Recent findings suggest that intravenous fluid composition affects risk of kidney injury and death for critically ill adults. Generally, the risk of kidney injury and death appears to be greater with semisyntheic colloids compared to crystalloids, and with saline compared to balanced crystalloids. Whether a liberal, restrictive, or hemodynamic responsivenessguided approach to fluid dosing improves outcomes during sepsis or major surgery remains uncertain.

Summary: As evidence on fluid resuscitation evolves, a reasonable approach would be to use primarily balanced crystalloids, consider $2-3$ liters for initial fluid resuscitation of hypovolemic or distributive shock, and use measures of anticipated hemodynamic response to guide further fluid administration.

\section{Keywords}

Intravenous fluid; resuscitation; saline; balanced crystalloids; colloids

\section{INTRODUCTION}

In 1832, Dr. Thomas Latta infused a solution of water, sodium, chloride, and bicarbonate through a metal tube into the veins of patients dying from cholera [1]. In the intervening 186 years, intravenous fluid administration has become a nearly ubiquitous therapy in critical care [2]. Each year more than 30 million patients receive intravenous fluid [3], and fluid therapy is fundamental to the care of patients with sepsis, hemorrhagic shock, and other lifethreatening illnesses.

Corresponding Author: Matthew W. Semler, MD, MSc, $116121^{\text {st }}$ Ave S., C-1216 MCN, Nashville, TN 37232-2650, Phone: (615)

322-3412, matthew.w.semler@ vanderbilt.edu.

Authors contributions: Drafting of the manuscript: J.D.C., R.M.B., M.W.S.; Critical revision of the manuscript for important intellectual content: J.D.C., R.M.B., M.W.S.

Conflicts of interest: none 
The potential negative effects of fluid administration have only more recently come into focus. Recent clinical trials indicate that the composition of each intravenous solution may affect organ function and patient outcomes. Starling's model of semi-permeable capillaries subject to hydrostatic and oncotic pressure gradients has increasingly been replaced by a more nuanced understanding of how fluid therapy relates to the endothelial glycocalyx layer [4*], the endothelial basement membrane, and the extracellular matrix [5]. Dynamic measures of fluid responsiveness have been shown to outperform static measures in identifying patients for whom a fluid bolus will increase cardiac output. Fluid overload has been associated with impaired organ function and decreased survival for critically ill patients across a range of diseases and settings.

This article reviews the recent evidence relating to intravenous fluid resuscitation in emergency and critical care settings, to help clinicians select the appropriate composition and dose of intravenous fluid for their critically ill patients.

\section{WHICH FLUID TO GIVE}

Intravenous solutions may be divided into two classes: (i) crystalloids, which are solutions of electrolytes in water that cross freely from the vascular space into the interstitum, and (ii) colloids, which contain large molecules that cannot permeate healthy capillary membranes.

\section{Crystalloids}

Because they are inexpensive, widely available, and (in most contexts) produce equivalent outcomes to colloid preparations, crystalloids are the most commonly administered intravenous fluid. More than 200 million liters of crystalloid are administered each year in the United States alone [2], and crystalloids are recommended as "first-line" for fluid resuscitation in such common critical illnesses as sepsis, hemorrhagic shock, and cardiac arrest.

\section{"Isotonic" Crystalloids}

There are two basic classes of "isotonic" crystalloid solution: saline ( $0.9 \%$ sodium chloride) and balanced crystalloids (e.g., lactated Ringer's, Hartmann's solution, Plasma-Lyte, Normosol, Isolyte). Saline contains $154 \mathrm{mmol} / \mathrm{L}$ of sodium and chloride - a chloride concentration approximately $50 \%$ greater than that of human extracellular fluid. In contrast, balanced crystalloids contain a sodium, potassium, chloride, and acid-base composition more similar to that of extracellular fluid. Balanced crystalloids achieve this by replacing chloride anions with buffers that are rapidly metabolized into bicarbonate (e.g., lactate and acetate) or excreted (e.g., gluconate). Historically, saline has been the most commonly administered intravenous crystalloid, especially in North America [6]. New data from randomized trials, however, challenge the safety of saline as the primary fluid therapy for acutely ill adults.

A recent, double-blind, randomized trial comparing balanced crystalloids to saline among patients undergoing major abdominal surgery was terminated after the enrollment of 60 patients because $97 \%$ percent of patients in the saline group required catecholamine infusion, compared to $67 \%$ in the balanced crystalloid group $(\mathrm{P}=0.03)\left[7^{*}\right]$. 
Two recent cluster-randomized, cluster-crossover trials compared balanced crystalloids to saline among nearly 30,000 acutely ill adults in the emergency department and intensive care units at a single center $[8 * *, 9 * *$. Both trials found that the incidence of death, new renal replacement therapy, and persistent renal dysfunction was lower with balanced crystalloids. For every 100 patients treated with intravenous fluid, using balanced crystalloids rather than saline appeared to spare one patient from death, new renal replacement therapy, or persistent kidney dysfunction. The difference between balanced crystalloids and saline appeared to be greatest for the most severely ill patients [10], patients who received the largest volumes of fluid, and patients with sepsis or septic shock.

Additional research is needed to determine (i) the mechanism by which crystalloid composition may affect clinical outcomes and (ii) the patient characteristics (comorbidities, acute conditions, hemodynamic and laboratory values, and markers of organ function) that identify patients most likely to benefit from balanced crystalloids versus saline [11-13]. Until further data are available, clinicians should consider using balanced crystalloids as "first-line" for fluid resuscitation.

\section{Bicarbonate}

The lower rates of metabolic acidosis, death, dialysis, and persistent renal dysfunction with crystalloid solutions containing a buffer raise the question of whether intravenous bicarbonate or bicarbonate-containing fluids may improve outcomes for some critically ill adults. A recent randomized trial examined the effect of intravenously administering $4.2 \%$ sodium bicarbonate to maintain arterial $\mathrm{pH}$ above 7.3 among critically ill adults with severe acidemia [14**. Bicarbonate therapy did not significantly reduce death or organ failure. The bicarbonate group, however, did experience a $16.7 \%$ absolute reduction in receipt of renal replacement therapy. Among the subgroup of patients with acute kidney injury, bicarbonate appeared to prevent the need for dialysis and decrease 28-day mortality. For critically ill adults with severe metabolic acidemia, especially those with non-anion gap acidosis or acute kidney injury, clinicians may choose to consider administration of sodium bicarbonate or an intravenous fluid containing bicarbonate as part of initial fluid resuscitation.

\section{Hypertonic Saline}

Concern about sodium and water overload from "isotonic" crystalloid resuscitation has generated interest in using small volumes of hypertonic saline solutions for resuscitation. Interest in hypertonic saline began during World War I [15] and resurged recently based on pre-clinical studies of hypertonic saline for traumatic brain injury and hemorrhagic or nonhemorhagic shock $[16,17]$. Among patients with elevated intracranial pressure, bolus administration of hypertonic saline temporarily lowers intracranial pressure, but does not appear to affect survival or cognitive outcomes [18-20]. Preclinical data suggest that, in septic shock, hypertonic saline infusion may exert beneficial effects on tissue hypoperfusion, oxygen consumption, endothelial dysfunction, and inflammation [21,22]. However, a recent randomized trial comparing 3.0\% sodium chloride to $0.9 \%$ sodium chloride for fluid resuscitation among 442 patients with septic shock was stopped after $42 \%$ of patients died in the hypertonic saline group compared with $37 \%$ in the isotonic saline group $(\mathrm{P}=0.12)$ [23*]. 
Currently, hypertonic saline represents a "first-line" treatment to temporarily reduce elevated intracranial pressure, but should not be used as the primary resuscitation fluid for hemorrhagic or non-hemorrhagic shock.

\section{Colloids}

Commonly administered colloids include derivatives of human plasma (albumin) and semisynthetic colloids (starches, gelatins, and dextrans). Compared with crystalloids, the theoretical benefit of colloid solutions is improved volume expansion, due to retention in the intravascular space. Recent evidence suggests, however, that the "volume-sparing" effect of colloids compared to crystalloids is less than anticipated for critically ill adults [24,25].

\section{Albumin}

Human serum albumin, a small protein synthesized by the liver, provides $75 \%$ of plasma colloid oncotic pressure, binds nitric oxide, and regulates inflammation [26]. A randomized trial comparing use of $4 \%$ albumin versus $0.9 \%$ sodium chloride among nearly 7,000 critically ill adults found that the albumin group received slightly less fluid but experienced no difference in 28-day mortality [24]. Subgroup analysis suggested a possible beneficial effect from albumin in patients with sepsis and a potential harmful effect in patients with traumatic brain injury [27]. A subsequent trial involving 1,818 patients with sepsis compared crystalloid solutions alone to crystalloid solutions plus daily administration of $20 \%$ albumin targeting a serum albumin level of $3 \mathrm{~g} / \mathrm{L}$ [28]. Mortality was identical in the two groups overall, but albumin appeared to reduce mortality among patients with shock at enrollment. Meta-analyses have suggested reduced mortality with albumin administration in patients with sepsis [29].

The high cost of albumin relative to crystalloid solutions suggests that, while albumin may be appropriate therapy for select subgroups, such as those with cirrhosis [30] and those undergoing liver transplantation, more research is needed before clinicians can consider albumin as a "first-line" fluid for resuscitation.

\section{Semisynthetic Colloids}

The expense and limited supply of human albumin solution led to the development of semisynthetic colloid solutions, which contain hydrolyzed bovine collagen (gelatins), glucose polymers (dextrans), or the maize-derived d-glucose polymer amylopectin (hydroxyethyl starches). Hydroxyethyl starch is the only semisynthetic colloid to have been evaluated in multiple large, randomized trials among critically ill adults. Several blinded trials comparing hydroxyethyl starch to crystalloid among critically ill adults found that the volume of fluid required for resuscitation was only slightly different between the colloid and crystalloid groups [25,31], perhaps because damage to the endothelial glycocalyx layer during critical illness prevented the hydroxyethyl starch from remaining in the vascular space. Moreover, the VISEP [31], CRYSTMAS [32], 6S [33], and CHEST [25] trials suggested that use of hydroxyethyl starch might increase the risk of acute kidney injury, need for renal replacement therapy, or mortality [34]. Pending further research, the cost and potential risks for increased acute kidney injury and mortality suggest clinicians should avoid semisynthetic colloids during fluid resuscitation of most critically ill patients. 


\section{HOW MUCH FLUID TO GIVE}

Once an intravenous solution has been selected, the next challenge faced by clinicians is to determine the "dose" to administer. The negative effects of fluid overload have been increasingly recognized [35-38]. To determine the point at which the potential benefits of further fluid administration are outweighed by the potential risks, clinicians must evaluate not only the patient's illness and underlying comorbidities, phase of fluid therapy [39], and anticipated hemodynamic response, but also the accumulating evidence from fluid management trials.

\section{Dose of Fluid}

Many of the clinical trials examining volume of intravenous fluid resuscitation have focused on adults with sepsis. In a landmark trial in 2001, sepsis patients treated with intravenous fluids, vasopressors, dobutamine, and blood transfusions to achieve physiologic targets experienced a lower mortality than the control group [40]. Patients in the intervention group received an average of 5.0 liters of intravenous fluid in the first six hours, compared to 3.5 liters in the control group. On the basis of this trial and subsequent studies, international guidelines for sepsis management recommend that patients with sepsis receive a rapid infusion of $30 \mathrm{ml} / \mathrm{kg}$ of crystalloid fluids in the first three hours after presentation [41], with ongoing fluid administration for patients who continue to exhibit a hemodynamic response [42]. Patients with sepsis or septic shock in the usual care groups in recent randomized clinical trials have received an average of $4.0-4.5$ liters of intravenous fluid in the first six hours [43-45].

Recent trials of fluid resuscitation in resource-limited settings, however, suggest potential negative effects from fluid bolus administration as a part of sepsis resuscitation. A randomized trial comparing a bolus of $5 \%$ albumin, a bolus of saline, and no fluid bolus among more than 3,000 children with severe febrile illness and impaired perfusion in Africa found that fluid boluses significantly increased 48-hour mortality [46]. A pilot trial of adults with sepsis in Zambia was stopped early due to excess mortality among patients with respiratory failure at baseline randomized to the protocolized fluid and vasopressor administration group [47]. Most recently, a trial among 212 patients in Zambia with sepsisinduced hypotension without respiratory failure found that administration of an average of 3.5 liters of fluid in the 6 hours after presentation increased 28-day mortality, compared to administration of an average of 2.0 liters [ $48 * *$ ]. A recent pilot trial found that restricting resuscitation fluid after initial sepsis resuscitation was feasible, and might decrease the risk for acute kidney injury [49]. Limiting fluid resuscitation and permissive hypotension appear to increase survival in other causes of shock, such as traumatic and non-traumatic hemorrhagic shock [50,51]. The optimal initial approach to fluid management in sepsis and septic shock remains uncertain [52*,53], and is the subject of ongoing clinical trials [54].

The optimal "dose" of intravenous fluid during invasive major surgery has also been the focus of recent study. Early trials comparing liberal intraoperative fluid management to a restrictive (zero-balanced) strategy reported decreased rates of post-operative cardiopulmonary and surgical-site complications with a restrictive approach [55]. In contrast, a recent multi-center trial comparing a restrictive versus liberal intravenous fluid 
regimen among 3,000 patients undergoing major abdominal surgery found that the restrictive approach increased the risk of acute kidney injury, without improving disability-free survival [56**]. The effects of a liberal, restrictive, or goal-directed approach to fluid management on outcomes of major abdominal surgery remains unclear, and further research is required.

\section{Fluid Responsiveness}

A primary goal of fluid resuscitation is to increase cardiac output and improve organ perfusion. Only half of hemodynamically unstable patients, however, experience an improvement in stroke volume with fluid administration [57]. Thus, researchers and clinicians are increasingly interested in techniques to predict which patients will experience hemodynamic improvement after fluid administration ("fluid responsiveness"). Early static measures such as central venous pressure and mixed venous oxygen saturation poorly predicted fluid responsiveness, and are no longer recommended for routine use [58,59]. Patient characteristics such as heart failure, hypothermia, and immunocompromise have some predictive ability [60]. Most recent research, however, has focused on "dynamic variables" that quantify changes in hemodynamic measurements or vascular structures following interventions to change ventricular pre-load, such as passive leg raise, changes during the respiratory cycle, mechanical ventilation maneuvers, or small fluid boluses.

Variation in pulse pressure and stroke volume with the respiratory cycle predict fluid responsiveness among non-spontaneously breathing mechanically ventilated patients in sinus rhythm [61]. A recent study found that measuring changes in pulse pressure variation or stroke volume variation that occur when increasing tidal volume from $6 \mathrm{~mL} / \mathrm{kg}$ predicted body weight to $8 \mathrm{~mL} / \mathrm{kg}$ may add value in predicting fluid responsiveness [62]. Ultrasound measurements that predict fluid responsiveness include global end-diastolic volume index [63], velocity time integral of the Doppler signal across the left ventricular outflow tract $[64,65]$, and carotid artery flow [66]. Respiratory variation in inferior vena cava diameter is a commonly used measurement, but a recent meta-analysis suggested limited ability to predict fluid responsiveness, particularly in spontaneously breathing patients [67].

Studies of fluid responsiveness have generally focused on short-term physiology rather than patient-centered outcomes. A recent meta-analysis of 1,652 patients enrolled in trials using a range of dynamic variables to guide fluid therapy suggested that the use of such techniques was associated with reduced duration of mechanical ventilation, length of stay, and mortality [68*]. A recent randomized trial comparing cardiac output-guided hemodynamic therapy during and after surgery to usual care among 734 patients undergoing major gastrointestinal surgery reported an absolute risk reduction in 30-day morbidity and mortality of 6.8\% [95\% CI, $-0.3 \%$ to $13.9 \%$ ] [69]. Conversely, a recent study using arterial waveform monitoring to guide fluid resuscitation in patients with septic shock or acute respiratory distress syndrome was stopped early for futility [70]. Additional research will be required to identify the optimal techniques for assessing fluid responsiveness for specific subgroups of patients, and to determine whether guiding fluid management using measures of fluid responsiveness improves clinical outcomes. 


\section{CONCLUSIONS}

Balanced crystalloids may decrease death and kidney dysfunction compared to saline among adults in the emergency department and intensive care unit. Albumin increases mortality in traumatic brain injury, but may eventually have a role as therapy for septic shock. Semisynthetic colloids appear to increase the risk of acute kidney injury, and should not be used for fluid resuscitation of most critically ill patients.

Determining the amount of fluid to administer during and after resuscitation requires a complex balancing of benefits and risks for each patient. Whether using dynamic measures of fluid responsiveness to guide therapy will improve patient outcomes remains unknown.

A reasonable approach for most emergency and critical care patients requiring fluid resuscitation is to use primarily balanced crystalloids, limit initial fluid boluses to 2-3 liters, and use available hemodynamic monitoring to guide further fluid administration.

\section{ACKNOWLEDGEMENTS}

Financial support and sponsorship: M.W.S. was supported in part by the National Heart, Lung, and Blood Institute (K23HL143053).

\section{REFERENCES}

1. Awad S, Allison SP, Lobo DN. The history of 0.9\% saline. Clin Nutr Edinb Scotl. 2008;27:179-88.

2. Myburgh JA, Mythen MG. Resuscitation fluids. N Engl J Med. 2013;369:1243-51. [PubMed: 24066745]

3. Glassford NJ, Bellomo R. The Complexities of Intravenous Fluid Research: Questions of Scale, Volume, and Accumulation. Korean J Crit Care Med. 2016;31:276-99.

4*. Byrne L, Obonyo NG, Diab SD, Dunster KR, Passmore MR, Boon A-C, et al. Unintended Consequences; Fluid Resuscitation Worsens Shock in an Ovine Model of Endotoxemia. Am J Respir Crit Care Med. 2018; This study compared fluid resuscitation with vasopressors to vasopressors alone in a hyperdynamic model of ovine endotoxemia. Compared to vasopressors alone, fluid resuscitation with $0.9 \%$ sodium chloride increased the dose of vasopressors needed to maintain mean arterial pressure, increased release of atrial natriuretic peptide, and increased serum markers of endothelial glycocalyx breakdown.

5. Woodcock TE, Woodcock TM. Revised Starling equation and the glycocalyx model of transvascular fluid exchange: an improved paradigm for prescribing intravenous fluid therapy. Br J Anaesth. 2012;108:384-94. [PubMed: 22290457]

6. Hammond NE, Taylor C, Saxena M, Liu B, Finfer S, Glass P, et al. Resuscitation fluid use in Australian and New Zealand Intensive Care Units between 2007 and 2013. Intensive Care Med. 2015;41:1611-9. [PubMed: 26077073]

7*. Pfortmueller CA, Funk G-C, Reiterer C, Schrott A, Zotti O, Kabon B, et al. Normal saline versus a balanced crystalloid for goal-directed perioperative fluid therapy in major abdominal surgery: a double-blind randomised controlled study. Br J Anaesth. 2018;120:274-83. [PubMed: 29406176] In the first randomized trial among patients undergoing major abdominal surgery, patients assigned to saline were more likely to receive vasopressors, and received higher doses of vasopressors to maintain the goal mean arterial pressure, compared to patients assigned to balanced crystalloids.

8**. Semler MW, Self WH, Wanderer JP, Ehrenfeld JM, Wang L, Byrne DW, et al. Balanced Crystalloids versus Saline in Critically Ill Adults. N Engl J Med. 2018;378:829-39. [PubMed: 29485925] This pragmatic trial comparing balanced crystalloids to saline among more than 15,000 critically ill adults at a single center found that use of balanced crystalloids decreased the incidence of death, renal replacement therapy, or persistent renal dysfunction by $1 \%$, compared 
with saline. This was the first large trial to compare balanced crystalloids to saline during critical illness, and the highest quality evidence to date to suggest that balanced crystalloids might result in better clinical outcomes than saline.

9**. Self WH, Semler MW, Wanderer JP, Wang L, Byrne DW, Collins SP, et al. Balanced Crystalloids versus Saline in Noncritically Ill Adults. N Engl J Med. 2018;378:819-28. [PubMed: 29485926] This pragmatic trial comparing balanced crystalloids to saline among more than 13,000 adults treated with fluid in the emergency department and hospitalized outside of an intensive care unit found no difference between groups in hospital-free days, but demonstrated a lower incidence of death, renal replacement therapy, and persistent renal dysfunction with balanced crystalloids, compared to saline. This is the first large trial to examine choice of crystalloid among noncritically ill adults, and appears to confirm the finding that balanced crystalloids result in better clinical outcomes than saline for fluid resuscitation during acute illness.

10. McKown AC, Huerta LE, Rice TW, Semler MW, Pragmatic Critical Care Research Group. Heterogeneity of Treatment Effect by Baseline Risk in a Trial of Balanced Crystalloids versus Saline. Am J Respir Crit Care Med. 2018;

11. Vincent J-L, De Backer D. Saline versus balanced solutions: are clinical trials comparing two crystalloid solutions really needed? Crit Care Lond Engl. 2016;20:250.

12. Hammond NE, Bellomo R, Gallagher M, Gattas D, Glass P, Mackle D, et al. The Plasma-Lyte 148 $\mathrm{v}$ Saline (PLUS) study protocol: a multicentre, randomised controlled trial of the effect of intensive care fluid therapy on mortality. Crit Care Resusc J Australas Acad Crit Care Med. 2017;19:239-46.

13. Zampieri FG, Azevedo LCP, Corrêa TD, Falavigna M, Machado FR, Assunção MSC de, et al. Study protocol for the Balanced Solution versus Saline in Intensive Care Study (BaSICS): a factorial randomised trial. Crit Care Resusc J Australas Acad Crit Care Med. 2017;19:175-82.

14**. Jaber S, Paugam C, Futier E, Lefrant J-Y, Lasocki S, Lescot T, et al. Sodium bicarbonate therapy for patients with severe metabolic acidaemia in the intensive care unit (BICAR-ICU): a multicentre, open-label, randomised controlled, phase 3 trial. Lancet Lond Engl. 2018;392:3140.This randomized trial examining sodium bicarbonate administration to critically ill adults with severe metabolic acidemia appeared to show that bicarbonate therapy decreased the receipt of renal replacement therapy, and may decrease mortality for the subgroup of patients with acute kidney injury. This moderately-sized trial provides the best evidence to date to inform the use of bicarbonate therapy for metabolic acidemia in critical illness.

15. Crile GW. THE PRESENT STATUS OF ANOCIATION: A CRITICAL REVIEW. Ann Surg. 1927;86:251-4. [PubMed: 17865723]

16. Järvelä K, Koskinen M, Kööbi T. Effects of hypertonic saline (7.5\%) on extracellular fluid volumes in healthy volunteers. Anaesthesia. 2003;58:878-81. [PubMed: 12911361]

17. de Felippe J, Timoner J, Velasco IT, Lopes OU, Rocha-e-Silva M. Treatment of refractory hypovolaemic shock by 7.5\% sodium chloride injections. Lancet Lond Engl. 1980;2:1002-4.

18. Bulger EM, May S, Brasel KJ, Schreiber M, Kerby JD, Tisherman SA, et al. Out-of-hospital hypertonic resuscitation following severe traumatic brain injury: a randomized controlled trial. JAMA. 2010;304:1455-64. [PubMed: 20924011]

19. Cooper DJ, Myles PS, McDermott FT, Murray LJ, Laidlaw J, Cooper G, et al. Prehospital hypertonic saline resuscitation of patients with hypotension and severe traumatic brain injury: a randomized controlled trial. JAMA. 2004;291:1350-7. [PubMed: 15026402]

20. Bulger EM, Jurkovich GJ, Nathens AB, Copass MK, Hanson S, Cooper C, et al. Hypertonic resuscitation of hypovolemic shock after blunt trauma: a randomized controlled trial. Arch Surg Chic Ill 1960. 2008;143:139-148; discussion 149.

21. Fang ZX, Li YF, Zhou XQ, Zhang Z, Zhang JS, Xia HM, et al. Effects of resuscitation with crystalloid fluids on cardiac function in patients with severe sepsis. BMC Infect Dis. 2008;8:50. [PubMed: 18419825]

22. Oliveira RP, Velasco I, Soriano FG, Friedman G. Clinical review: Hypertonic saline resuscitation in sepsis. Crit Care Lond Engl. 2002;6:418-23.

23*. Asfar P, Schortgen F, Boisramé-Helms J, Charpentier J, Guérot E, Megarbane B, et al. Hyperoxia and hypertonic saline in patients with septic shock (HYPERS2S): a two-by-two factorial, multicentre, randomised, clinical trial. Lancet Respir Med. 2017;5:180-90. [PubMed: 28219612] 
First large randomized trial to examine use of hypertonic saline for fluid resuscitation in septic shock, with no suggestion of beneficial effect for hypertonic saline.

24. Finfer S, Bellomo R, Boyce N, French J, Myburgh J, Norton R, et al. A comparison of albumin and saline for fluid resuscitation in the intensive care unit. N Engl J Med. 2004;350:2247-56.

[PubMed: 15163774]

25. Myburgh JA, Finfer S, Bellomo R, Billot L, Cass A, Gattas D, et al. Hydroxyethyl starch or saline for fluid resuscitation in intensive care. N Engl J Med. 2012;367:1901-11. [PubMed: 23075127]

26. Quinlan GJ, Martin GS, Evans TW. Albumin: biochemical properties and therapeutic potential. Hepatol Baltim Md. 2005;41:1211-9.

27. SAFE Study Investigators, Australian and New Zealand Intensive Care Society Clinical Trials Group, Australian Red Cross Blood Service, George Institute for International Health, Myburgh J, Cooper DJ, et al. Saline or albumin for fluid resuscitation in patients with traumatic brain injury. N Engl J Med. 2007;357:874-84. [PubMed: 17761591]

28. Caironi P, Tognoni G, Masson S, Fumagalli R, Pesenti A, Romero M, et al. Albumin replacement in patients with severe sepsis or septic shock. N Engl J Med. 2014;370:1412-21. [PubMed: 24635772]

29. Rochwerg B, Alhazzani W, Sindi A, Heels-Ansdell D, Thabane L, Fox-Robichaud A, et al. Fluid resuscitation in sepsis: a systematic review and network meta-analysis. Ann Intern Med. 2014;161:347-55. [PubMed: 25047428]

30. Caraceni P, Riggio O, Angeli P, Alessandria C, Neri S, Foschi FG, et al. Long-term albumin administration in decompensated cirrhosis (ANSWER): an open-label randomised trial. Lancet Lond Engl. 2018;391:2417-29.

31. Brunkhorst FM, Engel C, Bloos F, Meier-Hellmann A, Ragaller M, Weiler N, et al. Intensive insulin therapy and pentastarch resuscitation in severe sepsis. N Engl J Med. 2008;358:125-39. [PubMed: 18184958]

32. Guidet B, Martinet O, Boulain T, Philippart F, Poussel JF, Maizel J, et al. Assessment of hemodynamic efficacy and safety of $6 \%$ hydroxyethylstarch $130 / 0.4$ vs. $0.9 \% \mathrm{NaCl}$ fluid replacement in patients with severe sepsis: the CRYSTMAS study. Crit Care Lond Engl. 2012;16:R94.

33. Perner A, Haase N, Guttormsen AB, Tenhunen J, Klemenzson G, Åneman A, et al. Hydroxyethyl starch 130/0.42 versus Ringer's acetate in severe sepsis. N Engl J Med. 2012;367:124-34. [PubMed: 22738085]

34. Lewis SR, Pritchard MW, Evans DJ, Butler AR, Alderson P, Smith AF, et al. Colloids versus crystalloids for fluid resuscitation in critically ill people. Cochrane Database Syst Rev. 2018;8:CD000567. [PubMed: 30073665]

35. National Heart, Lung, and Blood Institute Acute Respiratory Distress Syndrome (ARDS) Clinical Trials Network, Wiedemann HP, Wheeler AP, Bernard GR, Thompson BT, Hayden D, et al. Comparison of two fluid-management strategies in acute lung injury. N Engl J Med. 2006;354:2564-75. [PubMed: 16714767]

36. Boyd JH, Forbes J, Nakada T, Walley KR, Russell JA. Fluid resuscitation in septic shock: a positive fluid balance and elevated central venous pressure are associated with increased mortality. Crit Care Med. 2011;39:259-65. [PubMed: 20975548]

37. Acheampong A, Vincent J-L. A positive fluid balance is an independent prognostic factor in patients with sepsis. Crit Care Lond Engl. 2015;19:251.

38. Bouchard J, Soroko SB, Chertow GM, Himmelfarb J, Ikizler TA, Paganini EP, et al. Fluid accumulation, survival and recovery of kidney function in critically ill patients with acute kidney injury. Kidney Int. 2009;76:422-7. [PubMed: 19436332]

39. Hoste EA, Maitland K, Brudney CS, Mehta R, Vincent J-L, Yates D, et al. Four phases of intravenous fluid therapy: a conceptual model. Br J Anaesth. 2014;113:740-7. [PubMed: 25204700]

40. Rivers E, Nguyen B, Havstad S, Ressler J, Muzzin A, Knoblich B, et al. Early goal-directed therapy in the treatment of severe sepsis and septic shock. N Engl J Med. 2001;345:1368-77. [PubMed: 11794169] 
41. Levy MM, Evans LE, Rhodes A. The Surviving Sepsis Campaign Bundle: 2018 update. Intensive Care Med. 2018;44:925-8. [PubMed: 29675566]

42. Rhodes A, Evans LE, Alhazzani W, Levy MM, Antonelli M, Ferrer R, et al. Surviving Sepsis Campaign: International Guidelines for Management of Sepsis and Septic Shock: 2016. Crit Care Med. 2017;45:486-552. [PubMed: 28098591]

43. Investigators ProCESS, Yealy DM, Kellum JA, Huang DT, Barnato DT AE, Weissfeld LA, et al. A randomized trial of protocol-based care for early septic shock. N Engl J Med. 2014;370:1683-93. [PubMed: 24635773]

44. ARISE Investigators, ANZICS Clinical Trials Group, Peake SL, Delaney A, Bailey M, Bellomo R, et al. Goal-directed resuscitation for patients with early septic shock. N Engl J Med. 2014;371:1496-506. [PubMed: 25272316]

45. Mouncey PR, Osborn TM, Power GS, Harrison DA, Sadique MZ, Grieve RD, et al. Trial of early, goal-directed resuscitation for septic shock. N Engl J Med. 2015;372:1301-11. [PubMed: 25776532]

46. Maitland K, Kiguli S, Opoka RO, Engoru C, Olupot-Olupot P, Akech SO, et al. Mortality after fluid bolus in African children with severe infection. N Engl J Med. 2011;364:2483-95. [PubMed: 21615299]

47. Andrews B, Muchemwa L, Kelly P, Lakhi S, Heimburger DC, Bernard GR. Simplified severe sepsis protocol: a randomized controlled trial of modified early goal-directed therapy in Zambia. Crit Care Med. 2014;42:2315-24. [PubMed: 25072757]

48**. Andrews B, Semler MW, Muchemwa L, Kelly P, Lakhi S, Heimburger DC, et al. Effect of an Early Resuscitation Protocol on In-hospital Mortality Among Adults With Sepsis and Hypotension: A Randomized Clinical Trial. JAMA. 2017;318:1233-40. [PubMed: 28973227] This trial is the first to examine protocolized fluid and vasopressor administration among adults presenting with sepsis in a resource-limited settings. The results appear to confirm the findings of two earlier trials, suggesting that even moderate volumes of fluid bolus administration increase sepsis mortality in resource-limited settings.

49. Hjortrup PB, Haase N, Bundgaard H, Thomsen SL, Winding R, Pettilä V, et al. Restricting volumes of resuscitation fluid in adults with septic shock after initial management: the CLASSIC randomised, parallel-group, multicentre feasibility trial. Intensive Care Med. 2016;42:1695-705. [PubMed: 27686349]

50. Tran A, Yates J, Lau A, Lampron J, Matar M. Permissive hypotension versus conventional resuscitation strategies in adult trauma patients with hemorrhagic shock: A systematic review and meta-analysis of randomized controlled trials. J Trauma Acute Care Surg. 2018;84:802-8. [PubMed: 29370058]

51. Villanueva C, Colomo A, Bosch A, Concepción M, Hernandez-Gea V, Aracil C, et al. Transfusion Strategies for Acute Upper Gastrointestinal Bleeding. N Engl J Med. 2013;368:11-21. [PubMed: 23281973]

52*. Seymour CW, Gesten F, Prescott HC, Friedrich ME, Iwashyna TJ, Phillips GS, et al. Time to Treatment and Mortality during Mandated Emergency Care for Sepsis. N Engl J Med. 2017;376:2235-44. [PubMed: 28528569] This large, observational study evaluated the association between timing of antibiotic and fluid administration among patients treated with a state-mandated sepsis protocol. Delays in antibiotic administration were associated with increased mortality, but delays in fluid bolus administration were not.

53. Evans IVR, Phillips GS, Alpern ER, Angus DC, Friedrich ME, Kissoon N, et al. Association Between the New York Sepsis Care Mandate and In-Hospital Mortality for Pediatric Sepsis. JAMA. 2018;320:358-67. [PubMed: 30043064]

54. Self WH, Semler MW, Bellomo R, Brown SM, deBoisblanc BP, Exline MC, et al. Liberal Versus Restrictive Intravenous Fluid Therapy for Early Septic Shock: Rationale for a Randomized Trial. Ann Emerg Med. 2018;

55. Brandstrup B, Tønnesen H, Beier-Holgersen R, Hjortsø E, Ørding H, Lindorff-Larsen K, et al. Effects of intravenous fluid restriction on postoperative complications: comparison of two perioperative fluid regimens: a randomized assessor-blinded multicenter trial. Ann Surg. 2003;238:641-8. [PubMed: 14578723] 
56**. Myles PS, Bellomo R, Corcoran T, Forbes A, Peyton P, Story D, et al. Restrictive versus Liberal Fluid Therapy for Major Abdominal Surgery. N Engl J Med. 2018;378:2263-74. [PubMed: 29742967] This pragmatic trial compared restrictive versus liberal fluid therapy among 3,000 adults undergoing major abdominal surgery, finding that restrictive fluid therapy did not improve disability-free survival but did increase the risk of acute kidney injury. These findings stand in contrast to a number of smaller trials suggesting restrictive fluid management might improve outcomes during abdominal surgery.

57. Marik P, Bellomo R. A rational approach to fluid therapy in sepsis. BJA Br J Anaesth. 2016;116:339-49. [PubMed: 26507493]

58. Marik PE, Cavallazzi R. Does the central venous pressure predict fluid responsiveness? An updated meta-analysis and a plea for some common sense. Crit Care Med. 2013;41:1774-81. [PubMed: 23774337]

59. Velissaris D, Pierrakos C, Scolletta S, De Backer D, Vincent JL. High mixed venous oxygen saturation levels do not exclude fluid responsiveness in critically ill septic patients. Crit Care Lond Engl. 2011;15:R177.

60. Leisman DE, Doerfler ME, Schneider SM, Masick KD, D’Amore JA, D'Angelo JK. Predictors, Prevalence, and Outcomes of Early Crystalloid Responsiveness Among Initially Hypotensive Patients With Sepsis and Septic Shock. Crit Care Med. 2018;46:189-98. [PubMed: 29112081]

61. Marik PE, Cavallazzi R, Vasu T, Hirani A. Dynamic changes in arterial waveform derived variables and fluid responsiveness in mechanically ventilated patients: a systematic review of the literature. Crit Care Med. 2009;37:2642-7. [PubMed: 19602972]

62. Myatra SN, Prabu NR, Divatia JV, Monnet X, Kulkarni AP, Teboul J-L. The Changes in Pulse Pressure Variation or Stroke Volume Variation After a "Tidal Volume Challenge" Reliably Predict Fluid Responsiveness During Low Tidal Volume Ventilation. Crit Care Med. 2017;45:415-21. [PubMed: 27922879]

63. Yu J, Zheng R, Lin H, Chen Q, Shao J, Wang D. Global end-diastolic volume index vs CVP goaldirected fluid resuscitation for COPD patients with septic shock: a randomized controlled trial. Am J Emerg Med. 2017;35:101-5. [PubMed: 27773350]

64. Jozwiak M, Depret F, Teboul J-L, Alphonsine J-E, Lai C, Richard C, et al. Predicting Fluid Responsiveness in Critically Ill Patients by Using Combined End-Expiratory and End-Inspiratory Occlusions With Echocardiography. Crit Care Med. 2017;45:e1131-8. [PubMed: 28857907]

65. Georges D, de Courson H, Lanchon R, Sesay M, Nouette-Gaulain K, Biais M. End-expiratory occlusion maneuver to predict fluid responsiveness in the intensive care unit: an echocardiographic study. Crit Care Lond Engl. 2018;22:32.

66. Barjaktarevic I, Toppen WE, Hu S, Aquije Montoya E, Ong S, Buhr R, et al. Ultrasound Assessment of the Change in Carotid Corrected Flow Time in Fluid Responsiveness in Undifferentiated Shock. Crit Care Med. 2018;

67. Long E, Oakley E, Duke T, Babl FE, Paediatric Research in Emergency Departments International Collaborative (PREDICT). Does Respiratory Variation in Inferior Vena Cava Diameter Predict Fluid Responsiveness: A Systematic Review and Meta-Analysis. Shock Augusta Ga. 2017;47:550-9.

68*. Bednarczyk JM, Fridfinnson JA, Kumar A, Blanchard L, Rabbani R, Bell D, et al. Incorporating Dynamic Assessment of Fluid Responsiveness Into Goal-Directed Therapy: A Systematic Review and Meta-Analysis. Crit Care Med. 2017;45:1538-45. [PubMed: 28817481] Systemic review and meta-analysis of 13 trials enrolling 1,652 reported an absolute risk reduction in mortality of $2.9 \%$ in favor of using dynamic measures of fluid responsiveness to guide fluid administration in the intensive care unit.

69. Pearse RM, Harrison DA, MacDonald N, Gillies MA, Blunt M, Ackland G, et al. Effect of a perioperative, cardiac output-guided hemodynamic therapy algorithm on outcomes following major gastrointestinal surgery: a randomized clinical trial and systematic review. JAMA. 2014;311:2181-90. [PubMed: 24842135]

70. Zhang Z, Ni H, Qian Z. Effectiveness of treatment based on PiCCO parameters in critically ill patients with septic shock and/or acute respiratory distress syndrome: a randomized controlled trial. Intensive Care Med. 2015;41:444-51. [PubMed: 25605469] 


\section{KEY POINTS}

- For most critically ill adults, crystalloids remain the "first-line" for fluid resuscitation.

- $\quad$ Balanced crystalloids may decrease the risk of death, renal replacement therapy, or persistent renal dysfunction compared with saline.

- Semisynthetic colloids may increase the risk of acute kidney injury or death compared with crystalloid solutions.

- Whether using measures of fluid responsiveness to guide fluid administration improves clinical outcomes for critically ill adults requires further research.

- A reasonable approach to fluid resuscitation for most acutely ill patients is to use primarily balanced crystalloids, giving 2-3 liters for initial resuscitation and dosing further fluid based on measures of anticipated hemodynamic response. 